\title{
Editorial
}

\section{Pertussis: A Continuing Hazard for Healthcare Facilities}

\author{
David J. Weber, MD, MPH; William A. Rutala, PhD, MPH
}

In $1999,7,288$ cases of pertussis were reported to the Centers for Disease Control and Prevention (CDC). ${ }^{1}$ High rates of pertussis, compared with other pediatric vaccinepreventable diseases, continued to occur even though, since 1995, the coverage rate with at least three doses of a pertussis-containing vaccine has been greater than $95 \%$ among US children aged 19 to 35 months. ${ }^{2}$

The continuing high rates of pertussis in the United States pose a challenge for infection control professionals to develop new strategies to recognize and manage nosocomial outbreaks of pertussis. In this issue, Martinez and colleagues describe a hospitalwide outbreak of a Bordetella pertussis-like illness and report that the use of postexposure prophylaxis with azithromycin was tolerated well and resulted in few healthcare workers (HCWs) missing work. ${ }^{3}$

\section{CHANGING EPIDEMIOLOGY OF PERTUSSIS: IMPORTANCE OF INFECTION IN ADULTS}

Since 1980 , the number of reported cases of pertussis has increased in the United States. Possible reasons for this rise could include increased awareness of pertussis among healthcare providers, increased use of more sensitive diagnostic tests, and better reporting of cases to health departments. ${ }^{1}$ Because vaccine-induced immunity wanes within 5 to 10 years after pertussis vaccination, most adolescents and adults are susceptible to disease. ${ }^{4,5}$ In contrast to the period 1990 through 1993, during 1994 through 1996 , the incidence of pertussis reported to the CDC among preschool-aged children did not change, but the incidence among adolescents aged 10 to 19 years and adults increased by more than $90 \% .{ }^{6}$ An analysis of surveillance data from 1989 to 1998 in Massachusetts also noted that the incidence in children remained stable, whereas the incidence in adolescents and adults increased; indeed, by 1998 , $92 \%$ of cases occurred in adolescents and adults. ${ }^{7}$

Pertussis is increasingly recognized as a case of chronic cough in adults.-11 Serological studies of prolonged cough illnesses in US adolescents and adults indicated that between $12 \%$ and $26 \%$ result from $B$ pertussis infection. ${ }^{12-15}$ Studies in other developed countries have produced similar results. ${ }^{11}$ The varying incidence rates reported depend, in part, on differences in study populations (eg, age), clinical definitions of disease (eg, duration of cough), and laboratory criteria for diagnosis. ${ }^{16}$

Pertussis in young children remains a serious disease. Common complications include pneumonia, 9.4\%; seizures, 2.3\%; and encephalopathy, $0.5 \%$. Death occurred in $0.9 \%$ of children, all under 6 months of age..$^{17}$ Adults with pertussis frequently experience prolonged cough, sleep disturbed by cough, and cough followed by choking or vomiting. ${ }^{18}$ Complications have been reported to be more common in adults than adolescents ( $28 \%$ vs $16 \%)$, with pneumonia occurring in $5 \%$ to $9 \%$ of persons older than 30 years of age. ${ }^{19}$ Subclinical pertussis may be common in adults with household exposure. ${ }^{20}$

Adolescents and young adults play an important role in the transmission of pertussis, because immunizationinduced immunity to pertussis wanes with increasing age, and because disease in adults frequently is not diagnosed or treated, as it often is atypical or mild. ${ }^{21}$

\section{LESSONS FROM NOSOCOMIAL OUTBREAKS}

Only limited data are available regarding the frequency of nosocomial exposures or outbreaks due to pertussis. Haiduven and colleagues reported that, between

From the Infectious Disease Division, Department of Medicine, University of North Carolina (UNC) School of Medicine, and the Department of Hospital Epidemiology, UNC Hospitals, Chapel Hill, North Carolina.

Address reprint requests to David Jay Weber, MD, MPH, Professor of Medicine, Pediatrics, and Epidemiology, CB \#7030 Burnett-Womack, 547, UNC-Chapel Hill, Chapel Hill, NC 27599-7030.

01-ED-192. Weber DJ, Rutala WA. Pertussis: a continuing hazard for healthcare facilities. Infect Control Hosp Epidemiol 2001;22:736-740. 
1989 and 1997, their medical center had 49 pertussis exposures that originated in pediatric units or clinics. ${ }^{22}$ Our experience is similar: 74 employees were exposed to 25 patients with pertussis between 1994 and $1998 .{ }^{23} \mathrm{We}$ found pertussis to be the third most common disease resulting in $\mathrm{HCW}$ exposure, following only varicellazoster and tuberculosis. Wright and colleagues assessed the incidence of pertussis infection in two cohorts of HCWs, based on serology, and reported annual incidence rates of $1.3 \%$ and $3.6 \%$ among residents and emergency department staff, respectively. ${ }^{24}$ Some employees had clinically unrecognized cases, whereas others had a history of a prolonged cough illness.

Multiple outbreaks of pertussis in healthcare facilities have been reported in the literature. ${ }^{25-35}$ These outbreaks have resulted from failure to recognize and isolate infected infants and children, failure to recognize and treat disease in staff members, and failure to institute control measures rapidly. Nosocomial acquisition of pertussis by HCWs has occurred during several outbreaks. ${ }^{26-28,32-35}$

Recommendations and protocols for the management of pertussis in healthcare facilities, including isolation, postexposure prophylaxis of patients and HCWs, and management of infected workers, have been published by the $\mathrm{CDC}^{36}$ and infectious disease experts ${ }^{22,37}$ and include the following: (1) isolate suspected or known infected patients using Droplet Precautions; (2) provide postexposure prophylaxis for all asymptomatic exposed employees; (3) evaluate all symptomatic employees for pertussis, and provide appropriate therapy; and (4) furlough symptomatic employees during the first 5 days of their therapy. The rationale for recommending Droplet Precautions for at least 5 days following the initiation of effective therapy has been strengthened by a study that detected $B$ pertussis DNA as far away as $4 \mathrm{~m}$ from the patient's bedside for up to 4 days following initiation of therapy. ${ }^{38}$

Recent advances that will have an impact on the management of pertussis in the hospital include the availability of new diagnostic tests, data demonstrating efficacy and safety of acellular pertussis vaccines in adults, and both in vitro and clinical data demonstrating efficacy of the newer macrolides (clarithromycin and azithromycin) for the therapy of pertussis.

\section{NEW DIAGNOSTIC TESTS}

The diagnosis of pertussis remains clinically challenging. Culture remains the "gold standard" but has poor sensitivity. The sensitivity of culture is affected by the disease stage, collection method, collection device, transport time and media, and incubation conditions. ${ }^{39}$ The ability to isolate pertussis decreases rapidly after the paroxysmal stage begins. Nasopharyngeal aspirates improve the yield compared to nasopharyngeal swabs. The preferred culture medium is charcoal agar supplemented with $10 \%$ horse blood and cephalexin (ReganLowe medium).
Direct fluorescent antibody testing on nasopharyngeal secretions has been used for rapid diagnosis, but this method suffers from low sensitivity (compared with culture) and low specificity. ${ }^{39,40}$

Serological methods have been used widely in clinical research but have limited application for clinical diagnosis or management. ${ }^{11}$ Enzyme-linked immunosorbent assay (ELISA) is the method of choice for $B$ pertussis serology. ${ }^{41}$ Compared with reference ELISA tests, commercial ELISA kits may yield false-positive or -negative results and need further improvement. ${ }^{42}$

Assays using the polymerase chain reaction (PCR) are rapidly becoming the diagnostic method of choice. ${ }^{11}$ Compared with culture, PCR has improved sensitivity while retaining excellent specificity. ${ }^{43,44}$ Because there have been few comparative studies on DNA-preparation methods and PCR assays, there currently is no consensus regarding which PCR assay is the best.

\section{ACELLULAR PERTUSSIS VACCINE IN ADULTS}

Acellular pertussis vaccines have been demonstrated to have similar or improved efficacy compared to the wholecell pertussis vaccine, with a lower frequency of febrile reactions. ${ }^{45-50}$ For this reason, only acellular pertussis vaccine is recommended in the current childhood immunization schedule in the United States. ${ }^{51}$ Reactogenicity of the whole-cell vaccine has long limited its use to children less than 7 years of age. Although whole-cell vaccine has been used successfully in conjunction with erythromycin prophylaxis to control a nosocomial outbreak, local reactions were common, and two adult vaccines developed systemic symptoms. ${ }^{27}$ In randomized, placebo-controlled trials, acellular pertussis vaccines have been shown to be both safe and highly immunogenic in adolescents and adults. ${ }^{52.57}$ Based on these studies, the targeted use of acellular pertussis vaccine in adolescents and adults at risk of pertussis, including HCWs, has been recommended. ${ }^{58-60}$ Immunization of HCWs with acellular pertussis vaccine has been used along with chemoprophylaxis to control nosocomial outbreaks. ${ }^{61,62}$ It is likely that, in the future, acellular pertussis vaccine will be recommended for $\mathrm{HCWs}$, either routinely or as an intervention during an outbreak. ${ }^{63}$

In several countries where whole-cell vaccine has been used, there is evidence that the incidence of pertussis is increasing despite high vaccine coverage. Sequence analysis of strains from both European countries and the United States has revealed polymorphism in the amino acid sequence of pertactin (prn) and the pertussis toxin (PT)-S1 subunit. ${ }^{6467}$ Nonvaccine genotypes of both prn and PT-S1 have gradually replaced the vaccine types in these countries. Evidence has suggested that whole-cell vaccine provides better protection against strains with the vaccine type prn than against strains with nonvaccine prn types. ${ }^{64}$ However, the exact role played by these genetically distinct strains in the resurgence of pertussis remains to be elucidated ${ }^{68}$ Rapid methods for identifying $B$ pertussis prn-gene variants have been described. ${ }^{69}$ 


\section{THERAPY FOR PERTUSSIS, INCLUDING POSTEXPOSURE PROPHYLAXIS}

Erythromycin is the only drug approved by the Food and Drug Administration for the treatment of pertussis; the estolate form is preferred by some clinicians because of superior pharmacokinetics. $B$ pertussis is highly susceptible in vitro to erythromycin. ${ }^{70-72}$ Erythromycin has been shown to decrease the duration of illness when administered early in the course of pertussis and to eliminate $B$ pertussis from the nasopharynx. For these reasons, erythromycin is considered the drug of choice for the treatment and prophylaxis of pertussis. $^{72-76}$

Erythromycin therapy of index cases in the community has been used successfully to reduce secondary cases of pertussis in households. ${ }^{77,78}$ Although chemoprophylaxis of exposed household members has been recommended, based on uncontrolled studies, a randomized placebo-controlled trial of erythromycin chemoprophylaxis for household contacts of children with culture-positive $B$ pertussis failed to demonstrate a reduction in clinical pertussis. ${ }^{79}$ Therapy of infected patients and chemoprophylaxis of exposed HCWs has been successful in terminating outbreaks in healthcare institutions. ${ }^{27,80}$ The potential epidemiological flaws in clinical trials of erythromycin prophylaxis have been reviewed. ${ }^{81}$

Erythromycin-resistant clinical isolates of $B$ pertussis have been reported, raising concern about the use of macrolides for therapy or prophylaxis ${ }^{82,83}$; however, recent surveys of $B$ pertussis strains demonstrate that macrolide resistance is uncommon. ${ }^{70-72} \mathrm{~B}$ pertussis is susceptible in vitro to trimethoprim-sulfamethoxazole, ${ }^{71,72}$ the newer macrolides azithromycin and clarithromcyin, ${ }^{70,72}$ and the quinolones levofloxacin, ciprofloxacin, ofloxacin, and gatifloxacin. ${ }^{72}$ Trimethoprim-sulfamethoxazole has been demonstrated to be effective in small clinical trials ${ }^{84}$ and therefore is the recommended alternative for treatment or prophylaxis of individuals intolerant to erythromycin ${ }^{73,76}$; however, its efficacy as a chemoprophylactic agent has not been evaluated. Small clinical trials suggest that clarithromycin and azithromycin also are effective for the treatment of pertussis. ${ }^{85}$ Although older studies had suggested that a 14-day course of erythromycin therapy was required from eradication of $B$ pertussis, recent trials have suggested that the following shorter courses of antibiotics are as successful as the standard 14-day course of erythromycin: 7 days of erythromycin esolate $(40 \mathrm{mg} / \mathrm{kg} / \mathrm{d}$; maximum dose $1 \mathrm{~g}),{ }^{86} 7$ days of clarithromycin, ${ }^{85}$ or 5 days of azithromycin. ${ }^{85}$ In this issue, Martinez and coworkers provide evidence that azithromycin was tolerated well by HCWs. ${ }^{3}$ Because of the high frequency of gastrointestinal intolerance with erythromycin, we also have switched to one of the newer macrolides (ie, azithromycin or clarithromycin).

\section{CONCLUSION}

Despite high rates of pediatric vaccine coverage, pertussis continues to be an important childhood dis- ease. Pertussis is now recognized as a common cause of prolonged cough in adults. Multiple hospital outbreaks have been described. Recognition of infection in patients may be facilitated by diagnostic testing using PCR. The drugs of choice for chemoprophylaxis at the current time are azithromycin or clarithromycin. The use of acellular pertussis vaccine for HCWs is likely to be recommended in the near future, either routinely or in outbreak settings.

\section{REFERENCES}

1. Centers for Disease Control and Prevention. Summary of notifiable diseases, United States, 1999. MMWR 1999;48:1-101.

2. Herrera GA, Smith P, Daniels D, Klevens RM, Coronado V, McCauley $M$, et al. National, state, and urban area vaccination coverage levels among children aged 19-35 months: United States, 1998. MMWR $2000 ; 49(9): 1-23$.

3. Martinez SM, Kemper CA, Haiduven D, Cody SH, Deresinski SC. Azithromycin prophylaxis during a hospitalwide outbreak of a pertussislike illness. Infect Control Hosp Epidemiol 2001;22:781-783.

4. Jenkinson D. Duration of effectiveness of pertussis vaccine: evidence from a 10 year community study. Br Med J (Clin Res Ed) 1988;296:612614.

5. He Q, Viljanen MK, Nikkari S, Lyytikainen R, Mertsola J. Outcomes of Bordetella pertussis infection in different age groups of an immunized population. I Infect Dis 1994;170:873-877.

6. Guris D, Strebel PM, Bardenheier B, Brennan M, Tachdjian R, Finch E, et al. Changing epidemiology of pertussis in the United States: increasing reported incidence among adolescents and adults, 1990-1996. Clin Infect Dis 1999;28:1230-1237.

7. Yih WK, Lett SM, des Vignes FN, Garrison KM, Sipe PL, Marchant CD. The increasing incidence of pertussis in Massachusetts adolescents and adults, 1989-1998. J Infect Dis 2000;182:1409-1416.

8. Cherry JD. Epidemiology, clinical, and laboratory aspects of pertussis in adults. Clin Infect Dis 1999;28(suppl 2):S112-S117.

9. Wright SW. Pertussis infection in adults. South Med J 1998;91:702-708.

10. Senzilet LD, Halperin SA, Spika JS, Alagaratnam M, Morris M, Smith B. Pertussis is a frequent cause of prolonged cough illness in adults and adolescents. Clin Infect Dis 2001;32:1691-1697.

11. Birkebaek NH. Bordetella pertussis in the aetiology of chronic cough in adults: diagnostic methods and clinic. Dan Med Bull 2001;48:77-80.

12. Mink CM, Cherry JD, Christenson P, Lewis K, Pineda E, Shlian D, et al. A search for Bordetella pertussis infection in university students. Clin Infect Dis 1992;14:464-471.

13. Rosenthal S, Strebel P, Cassiday P, Sanden G, Brusuelas K, Wharton M. Pertussis infection among adults during the 1993 outbreak in Chicago.J Infect Dis 1995;171:1650-1652.

14. Wright SW, Edwards KM, Decker MD, Zeldin MH. Pertussis infection in adults with persistent cough. JAMA 1995;273:1044-1046.

15. Nennig ME, Shinefield HR, Edwards KM, Black SB, Fireman BH. Prevalence and incidence of adult pertussis in an urban population. JAMA 1996;275:1672-1674.

16. Edwards KM. Is pertussis a frequent cause of cough in adolescents and adults? Should routine pertussis immunization be recommended? Clin Infect Dis 2001;32:1698-1699.

17. Halperin SA, Wang EE, Law B, Mills E, Morris R, Dery P, et al. Epidemiology features of pertussis in hospitalized patients in Canada, 1991-1997: report of the Immunization Monitoring Program-Active (IMPACT). Clin Infect Dis 1999;28:1238-1243.

18. Postels-Multani S, Schmitt HJ, Wirsing von Konig $\mathrm{CH}$, Bock HL, Bogaerts $H$. Symptoms and complications of pertussis in adults. Infection 1995;23:139-142.

19. De Serres G, Shadmani R, Duval B, Boulianne N, Dery P, Douville Fradet M, et al. Morbidity of pertussis in adolescents and adults. J Infect Dis 2000;182:174-179.

20. Christie CD, Baltimore RS. Pertussis in neonates. Am J Dis Child 1989;143:1199-1202.

21. Black S. Epidemiology of pertussis. Pediatr Infect Dis J 1997;16(suppl 4):S85-S89.

22. Haiduven DJ, Hench CP, Simpkins SM, Stevens DA. Standardized management of patients and employees exposed to pertussis. Infect Control Hosp Epidemiol 1998;19:861-864.

23. Weber DJ, Rutala WA, Kanoy C, Consoli S. Infectious disease exposure evaluations at a university hospital. Infect Control Hosp Epidemiol 2000;21:141. Abstract.

24. Wright SW, Decker MD, Edwards KM. Incidence of pertussis infection 
in healthcare workers. Infect Control Hosp Epidemiol 1999;20:120-123.

25. Altemeier WA, Ayoub EM. Erythromycin prophylaxis in pertussis. Pediatrics 1977;59:623-625.

26. Kurt TL, Yeager AS, Guenette S, Dunlop S. Spread of pertussis by hospital staff. JAMA 1972;221:264-267.

27. Linnemann CC Jr, Ramundo N, Perlstein PH, Minton SD, Englender GS Use of pertussis vaccine in an epidemic involving hospital staff. Lancet 1975;2:540-543.

28. Valenti WM, Pincus PH, Messner MK. Nosocomial pertussis: possible spread by a hospital visitor. Am J Dis Child 1980;134:520-521.

29. Halsey NA, Welling MA, Lehman RM. Nosocomial pertussis: a failure of erythromycin treatment and prophylaxis. Am J Dis Child 1980;134:521522

30. Fisher MC, Long SS, McGowan KL, Kaselis E, Smith DG. Outbreak of pertussis in a residential facility for handicapped people. $J$ Pediatr 1989:114:934-939.

31. Addiss DG, Davis JP, Meade BD, Burstyn DG, Meissner M, Zastrow JA, et al. A pertussis outbreak in a Wisconsin nursing home. J Infect Dis 1991:164:704-710.

32. Tanaka Y, Fujinaga K, Goto A, Iwai H, Aoyama T, Murase $\mathrm{Y}$, et al. Outbreak of pertussis in a residential facility for handicapped people. Devel Biol Stand 1991:73:329-332.

33. Christie CD, Glover AM, Willke MJ, Marx ML, Reising SF, Hutchinson NM. Containment of pertussis in the regional pediatric hospital during the Greater Cincinnati epidemic of 1993. Infect Control Hosp Epidemiol 1995; $16: 556-563$

34. Matlow AG, Nelson S, Wray R, Cox P. Nosocomial acquisition of pertussis diagnosed by polymerase chain reaction. Infect Control Hosp Epidemiol 1997; 18:715-716.

35. Nouvellon M, Gehanno JF, Pestel Caron M, Weber C, Lemeland JF, Guiso N. Usefulness of pulsed-field gel electrophoresis in assessing nosocomial transmission of pertussis. Infect Control Hosp Epidemiol 1999;20:758-760

36. Bolyard EA, Tablan OC, Williams WW, Pearson ML, Shapiro CN Deitchmann D. Guideline for infection control in healthcare personnel, 1998. Hospital Infection Control Practices Advisory Committee. Infect Control Hosp Epidemiol 1998;19:407-463.

37. Weber DJ, Rutala WA. Management of healthcare workers exposed to pertussis. Infect Control Hosp Epidemiol 1994;15:411-415.

38. Aintablian N, Walpita P, Sawyer MH. Detection of Bordetella pertussis and respiratory syncytial virus in air samples from hospital rooms. Infect Control Hosp Epidemiol 1998;19:918-923.

39. Muller FM, Hoppe JE, Wirsing von Konig CH. Laboratory diagnosis of pertussis: state of the art in 1997. J Clin Microbiol 1997;35:24352443.

40. Kerr JR, Matthews RC. Bordetella pertussis infection: pathogenesis, diagnosis, management, and the role of protective immunity. Eur $J$ Clin Microbiol Infect Dis 2000;19:77-88.

41. Hallander HO. Microbiological and serological diagnosis of pertussis. Clin Infect Dis 1999;28(suppl 2):S99-S106.

42. Kosters K, Riffelmann M, Dohrn B, von Konig CH. Comparison of five commercial enzyme-linked immunosorbent assays for detection of antibodies to Bordetella pertussis. Clin Diagn Lab Immunol 2000;7:422426.

43. Lind-Brandberg $\mathrm{L}$, Welinder-Olsson $\mathrm{C}$, Lagergard $\mathrm{T}$, Taranger $\mathrm{J}$, Trollfors B, Zackrisson G. Evaluation of PCR for diagnosis of Bordetella pertussis and Bordetella parapertussis infections. J Clin Microbiol 1998;36:679-683

44. Heininger U, Schmidt-Schlapfer G, Cherry JD, Stehr K. Clinical validation of a polymerase chain reaction assay for the diagnosis of pertussis by comparison with serology, culture, and symptoms during a large pertussis vaccine efficacy trial. Pediatrics 2000;105:E31.

45. Dennehy PH. Active immunization in the United States: developments over the past decade. Clin Microbiol Rev 2001;14:872-908.

46. Centers for Disease Control and Prevention. Pertussis vaccination: use of acellular pertussis vaccines among infants and children. Recommendations of the Advisory Committee on Immunization Practices. $M M W R$ 1997;46(RR-7):1-25.

47. Cherry JD. Comparative efficacy of acellular pertussis vaccines: an analysis of recent trials. Pediatr Infect Dis J 1997;16:S90-S96.

48. Heininger U. Recent progress in clinical and basic pertussis research. Eur J Pediatr 2001;160:203-213.

49. Decker MD, Edwards KM. Acellular pertussis vaccines. Pediatr Clin North Am 2000;47:309-335.

50. Schleiss MR, Dahl K. Acellular pertussis vaccines. Curr Probl Pediatr 2000;30:181-201.

51. Centers for Disease Control and Prevention. Recommended childhood immunization schedule-United States, 2001. MMWR 2001;50:710,19

52. Keitel WA, Muenz LR, Decker MD, Englund JA, Mink CM, Blumberg $\mathrm{DA}$, et al. A randomized clinical trial of acellular pertussis vaccines in healthy adults: dose-response comparisons of 5 vaccines and implications for booster immunization. J Infect Dis 1999;180:397-403.

53. Halperin SA Smith B, Russell M, Hasselback P, Guasparini R, Skowronski D, et al. An adult formulation of a five-component acellular pertussis vaccine combined with diphtheria and tetanus toxoids is safe and immunogenic in adolescents and adults. Vaccine 2000;18:1312-1319.

54. Rothstein EP, Anderson EL, Decker MD, Poland GA, Reisinger KS. An acellular pertussis vaccine in healthy adults: safety and immunogenicity. Pennridge Pediatric Associates. Vaccine 1999;17:2999-3006

55. Van der Wielen M, Van Damme P, Joossens E, Francois G, Meurice F, Ramalho A. A randomized controlled trial with a diphtheria-tetanusacellular pertussis (dTpa) vaccine in adults. Vaccine 2000:18:20752082.

56. Tran Minh NN, He Q, Edelman K, Putto-Laurila A, Arvilommi H, Viljanen MK, et al. Immune responses to pertussis antigens eight years after booster immunization with acellular vaccines in adults. Vaccine 2000;18:1971-1974.

57. Turnbull FM, Heath TC, Jalaludin BB, Burgess MA. Ramalho AC. A randomized trial of two acellular pertussis vaccines (dTpa and pa) and a licensed diphtheria-tetanus vaccine (Td) in adults. Vaccine 2000;19:628636

58. Gardner P. Implications for acellular pertussis vaccines in adults: the case for selective, rather than universal, recommendations. Clin Infect Dis 1999:28 (suppl 2):S131-S135.

59. Gardner P. Issue related to the decennial tetanus-diphtheria toxoid booster recommendations in adults. Infect Dis Clin North Am 2001;15:143-153

60. Campins-Marti M, Cheng HK, Forsyth K, Guiso N, Halperin S, Huang LM, et al. Recommendations are needed for adolescent and adult pertussis immunization: rationale and strategies for consideration. Vaccine 2001:20:641-646.

61. Shefer A, Dales L, Nelson M, Werner B, Baron R, Jackson R. Use and safety of acellular pertussis vaccine among aduit hospital staff during an outbreak of pertussis. J Infect Dis 1995:171:1053-1056.

62. Christie CD, Garrison KM, Kiely L, Gupta RK, Heubi J, Marchant CD A trial of acellular pertussis vaccine in hospital workers during the Cincinnati pertussis epidemic of 1993. Clin Infect Dis 2001;33:9971003.

63. Orenstein WA. Pertussis in adults: epidemiology, signs, symptoms, and implications for vaccination. Clin Infect Dis 1999;28(suppl 2):S147S150.

64. Mooi FR, van Oirschot H, Heuvelman K, van der Heide HG, Gaastra W, Willems RJ. Polymorphism in the Bordetella pertussis virulence factors P.69/pertactin and pertussis toxin in The Netherlands: temporal trends and evidence for vaccine-driven evolution. Infect Immun 1998;66:670675.

65. Mooi FR, He Q, van Oirschot H, Mertsola J. Variation in the Bordetella pertussis virulence factors pertussin toxin and pertactin in vaccine strains and clinical isolates in Finland. Infect Immun 1999;67:31333134

66. Mastrantonio P, Spigaglia $\mathrm{P}$, van Oirschot $\mathrm{H}$, van der Heide $\mathrm{HG}$, Heuvelman K, Stefanelli P, et al. Antigenic variants in Bordetella pertussis strains isolated from vaccinated and unvaccinated children. Microbiology 1999;145:2069-2075.

67. Cassiday P, Sanden G, Heuvelman K, Mooi F, Bisgard KM, Popovic T Polymorphism in Bordetella pertussis pertactin and pertussis toxin virulence factors in the United States, 1935-1999. J Infect Dis 2000;182:14021408.

68. Mooi FR, van Loo IH, King AJ. Adaptation of Bordetella pertussis to vaccination: a cause for its reemergence? Emerg Infect Dis 2001;7(suppl 3):526-528.

69. Makinen J, Vilianen MK, Mertsola J, Arvilommi H, He Q. Rapid identification of Bordetella pertussis pertactin gene variants using lightcycler real-time polymerase chain reaction combined with melting curve analysis and gel electrophoresis. Emerg Infect Dis 2001;7:952-958.

70. Hoppe JE, Bryskier A. In vitro susceptibilities of Bordetella pertussis and Bordetella parapertussis to two ketolides (HMR 3004 and HMR 3647), four macrolides (azithromycin, clarithromycin, erythromycin A, and roxithromycin) and two ansamycins (rifampin and rifapentine). Antimicrob Agents Chemother 1998;42:965-966.

71. Brett M, Short P, Beatson S. The comparative in-vitro activity of roxithromycin and other antibiotics against Bordetella pertussis. I Antimicrob Chemother 1998;41 (suppl B):23-27.

72. Gordon KA, Fusco J, Biedenbach DJ, Pfaller MA, Jones RN Antimicrobial susceptibility testing of clinical isolates of Bordetella pertussis from Northern California: report from the SENTRY Antimicrobial Surveillance Program. Antimicrob Agents Chemother 2001:45:3599-3600.

73. American Academy of Pediatrics. Pertussis. In: Pickering LK, ed. 2000 Red Book: Report of the Committee on Infectious Diseases. 25th 
ed. Elk Grove Village, IL: American Academy of Pediatrics; 2000:435448.

74. The choice of antibacterial drugs. Med Lett Drugs Ther 2001;43:69-78.

75. Kerr JR, Preston NW. Current pharmacotherapy of pertussis. Expert Opin Pharmacother 2001;2:1275-1282.

76. Irwin RS, Madison JM. The diagnosis and treatment of cough. $N$ Engl J Med 2000;343:1715-1721.

77. Wirsing von Konig CH, Postels-Multani S, Bock HL, Schmitt HJ. Pertussis in adults: frequency of transmission after household exposure. Lancet 1995;346:1326-1329.

78. Wirsing von Konig $\mathrm{CH}$, Postels-Multani S, Bogaerts H, Bock HL, Laukamp S, Kierderle S, et al. Factors influencing the spread of pertus sis in households. Eur J Pediatr 1998;157:391-394.

79. Halperin SA, Bortolussi R, Langley JM, Eastwood BJ, de Serres G. A randomized, placebo-controlled trial of erythromycin estolate chemoprophylaxis for household contacts of children with culture-positive Bordetella pertussis infection. Pediatrics 1999;104:E42.

80. Steketee RW, Wassilak SG, Adkins WN Jr, Burstyn DG, Manclark CR, Berg J, et al. Evidence for a high attack rate and efficacy of erythromycin prophylaxis in a pertussis outbreak in a facility for the devel- opmentally disabled. J Infect Dis 1988;157:434-440.

81. Dodhia $H$, Miller E. Review of the evidence for the use of erythromycin in the management of persons exposed to pertussis. Epidemiol Infect 1998;120:143-149.

82. Lewis K, Saubolle MA, Tenover FC, Rudinsky MF, Barbour SD, Cherry JD. Pertussis caused by an erythromycin-resistant strain of Bordetella pertussis. Pediatr Infect Dis J 1995;14:388-391.

83. Korgenski EK, Daly JA. Surveillance and detection of erythromycin resistance in Bordetella pertussis isolates recovered from a pediatric population in the Intermountain West region of the United States. J Clin Microbiol 1997;35:2989-2991.

84. Hoppe JE, Halm U, Hagedorn HJ, Kraminer-Hagedorn A. Comparison of erythromycin ethylsuccinate and co-trimoxazole for treatment of pertussis. Infection 1989;17:227-231.

85. Aoyama T, Sunakawa K, Iwata S, Takeuchi Y, Fujii R, Efficacy of shortterm treatment of pertussis with clarithromycin and azithromycin. $J$ Pediatr 1996;129:761-764.

86. Halperin SA, Bortolussi R, Langley JM, Miller B, Eastwood B. Seven days of erythromycin estolate is as effective as fourteen days for the treatment of Bordetella pertussis infections. Pediatrics 1997;100:65-71. 